\title{
From Shakespeare to Star Trek and beyond: a Medline search for literary and other allusions in biomedical titles
}

Neville W Goodman

Southmead
Hospital, Bristol,
BS10 5NB
Neville W
Goodman
consultant
anaesthetist
Nev.W.Goodman@
bris.ac.uk

BMJ 2005;331:1540-2

\begin{abstract}
Objectives To document biomedical paper titles containing literary and other allusions.

Design Retrospective survey.

Setting Medline (1951 to mid-2005) through Dialog Datastar.

Main outcome measure Allusions to Shakespeare, Hans Christian Andersen, proverbs, the Bible, Lewis Carroll, and movie titles, corrected and scaled for five year periods $1950-4$ to $2000-4$.

Results More than 1400 Shakespearean allusions exist, a third of them to "What's in a name" and another third to Hamlet-mostly to "To be or not to be." The trend of increasing use of allusive titles, identified from Shakespeare and Andersen, is paralleled by allusions to Carroll and proverbs; the trend of biblical allusions is also upward but is more erratic. Trends for newer allusions are also upwards, including the previously surveyed "paradigm shift." Allusive titles are likely to be to editorial or comment rather than to original research.

Conclusions The similar trends are presumably a mark of a particular learnt author behaviour. Newer allusions may be becoming more popular than older ones. Allusive titles can be unhelpful to reviewers and researchers, and many are now clichés. Whether they attract readers or citations is unknown, but better ways of gaining attention exist.
\end{abstract}

Atkin, believing that "catchy titles work best," looked for "paradigm shift" in the titles of papers. ${ }^{1}$ But catchy titles using literary allusions predate paradigm shift (first use 1980) by a good few years. (Strictly, these are not allusions-implicit or indirect references-but the word "references" has its own meaning in medical publishing, so allusions will have to do.) A 1983 paper about titling biomedical papers, "The title. What's in a name?", gives a clue to an unsurprising allusive source, William Shakespeare, but many others exist.

\section{Methods}

I searched Medline (1951 to date) by using Dialog Datastar in the second half of July 2005. I thought of possible allusions and then searched methodically for them, limiting the search to titles and using the most appropriate method of searching. I mainly used NEXT, which locates words following one another within five words. For some searches, the only way of identifying allusions was to count from scanned lists of titles; for example, searching for many short common words is not possible, even in explicit phrases such as "to treat." I used Boolean operators as appropriate.

To compare the more popular allusions, I corrected the number of hits for the total number of papers published per five years: 1950-4 counted as unity, and the last complete period 2000-4 counted as 5.65. I adjusted this corrected number arbitrarily to 100 for each com-

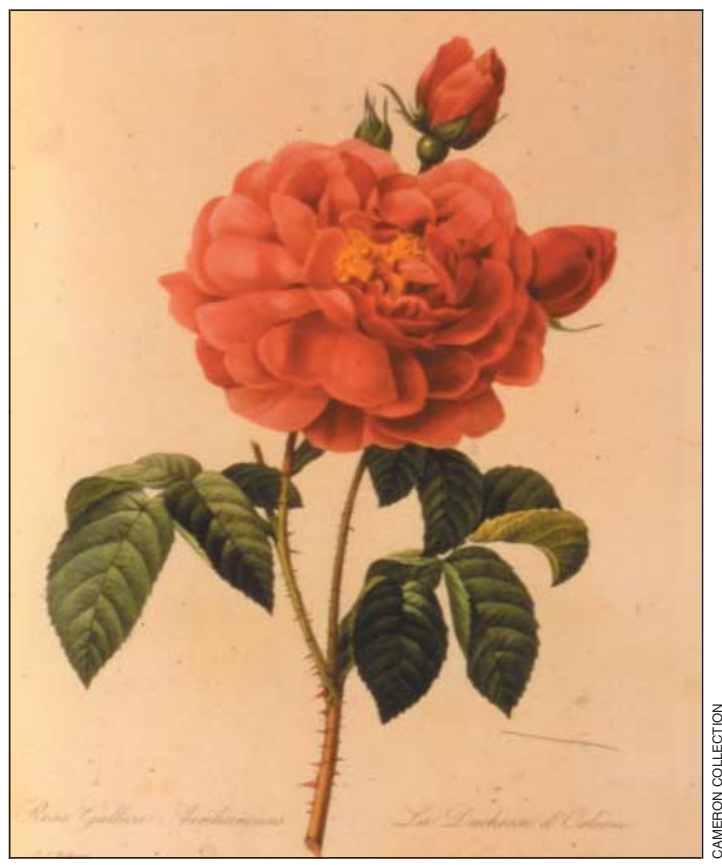

A "rose is a rose is a rose is a rose," but exactly what is a gastric adenocarcinoma? (J Surg Oncol 1998;68(3):141-3)

pared allusion. I made no formal statistical comparisons. Titles from 2005 were not included in these comparisons, but some are included in totals mentioned in the text.

\section{Results}

\section{Shakespearean allusions}

I found 559 allusions to "What's in a name? That which we call a rose by any other name would smell as sweet" (Romeo and Juliet). Almost all contain "What's in a name;" and a few are imaginative--for example, "A flap by any other name would be as rose-colored."

Hamlet is a rich seam. "To be or not to be; that is the question" is possibly the best known quotation in English literature, but awkwardly the allusion does not need the second part of the quotation. I thought of single syllable verbs that indicate medical decisions: I found 244 "to treat or not to treat," 96 "screen," 53 "tell," and 78 assorted others. Clone first appeared in 1997. Test gets 3505 , mostly irrelevant and too many to scan but including the outrageous pun, "To test or NOD-2 test: what are the questions?"

"Whether 'tis nobler in the mind to suffer the slings and arrows of outrageous fortune" provides 11 titles, including, "Is it Ig Nobler for science to suffer the slings $\&$ arrows of outrageous foolery?", which, coming from $J A M A$, could not be claimed as a product of the medical tabloid press. Five seas of troubles and two consumma-

Supporting material is on bmj.com 
tions devoutly to be wished come before the next nugget: "To sleep: perchance to dream: ay, there's the rub," providing 49, including sleeping to "gain creative insight" and "increase the risk of coronary events."

I found five mortal coils, but one is a paper about Shakespeare. No whips and scorns, no law's delay, and no insolence of office occurred, but I found four undiscovered countries. Altogether, "To be or not to be" has spawned 564 allusive titles.

I found 22 other assorted allusions to Hamlet, the most common of which was "something rotten" (9), and appropriately one of those was Danish. Methinks appears in four titles, one-"Methinks it is like a folding curve"-as an allusion to Hamlet's dialogue with Polonius. I found no politic worms.

"Much ado about nothing" occurs 171 times; the first, from 1967, is "Much ado about the null hypothesis." "Breast cancer screening: all's well that ends well, or much ado about nothing?" leads to 23 all's wells. The same allusions have occurred to different authors: from 1990 comes "Telomeres. All's well that ends well," and from 1991 "The telomere in cancer. All's not well that doesn't end well." Sometimes consonance may not be an allusion: did the author of "seeing gel wells well" have Shakespeare in mind?

The Merchant of Venice provides "quality of mercy" and "pound of flesh," with 17 between them, and "all that glisters." Six of the 16 glisters prefer the more modern glistens, and quite a lot of originality exists: "All that is excreted does not glister: or why do we keep on collecting urine to measure creatinine clearance?" I found 17 "Love's labours lost." Obstetricians have so far ignored "Once more unto the breech," whose only use refers to firearms, but "Once more unto the breach" (Henry V) occurs 13 times.

Exhaustive (and exhausting) use of a dictionary of quotations would identify more, but I did find some others, including four out damned spots (Macbeth). The first was from 1951 and one of the earliest: a BMJ editorial commenting on the use of statistics in medical journals. Nobody has yet used "nothing will come of nothing" (King Lear). The grand total of Shakespearian allusive titles is more than 1400 .

\section{Other allusions}

Shakespeare was not the only author to mention roses: Gertrude Stein (1874-1946) is famous for "a rose is a rose is a rose." I found 28 allusions, including "A rose is a rose is a rose is a rose, but exactly what is a gastric adenocarcinoma?"

Hans Christian Andersen's (1805-75) morality tale, The Emperor's New Clothes, lets us compare with Shakespeare an allusion that sufficiently predates Medline224 once papers about emperor penguins and about real emperors with interesting ailments have been rejected. The first uses were in 1966, "The emperor's new clothes, or an inquiry into the present status of tumor viruses and virus tumors" and "The subphrenic spaces and the emperor's new robes," but since then emperors have been dressed, attired, redressed, partially clad, defrocked, disrobing, or naked. Some do not refer to clothes at all; for example, "Next emperor, please! No end to retrospective diagnostics." All sorts of things have substituted for clothes, including isodose curves, bone densitometry, the lateral ligaments of the rectum-and mentorship. The title "Mentorship-is it a

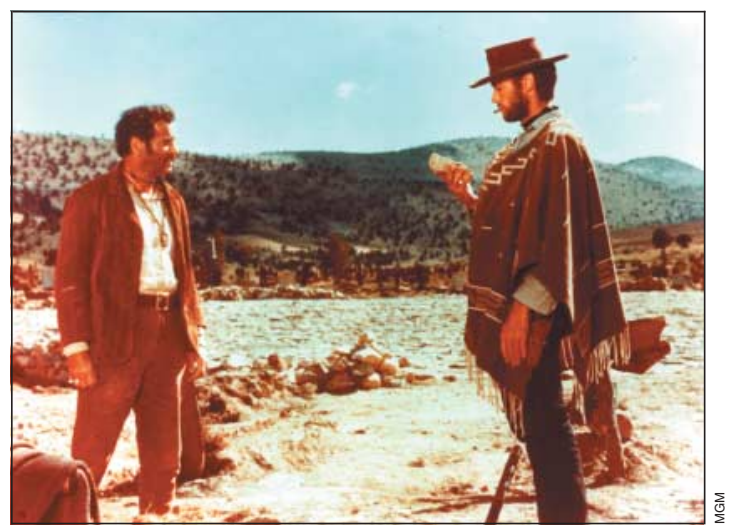

A fistful of T cells (Br J Rheumatol 1998;37(6):602-11)

case of the emperor's new clothes or a rose by any other name?" mixes Andersen and Shakespeare. An echo of Atkin's paper appears in "Evolutionary psychology: the emperor's new paradigm."

A more recent and popular allusion is variation on Brian Clark's "Whose life is it anyway?" (1978). I found 249. Of these, 31 are the straight quote, but the first use, in 1980, was different, "Whose ethic is it anyway?"

\section{Non-literary allusions}

The cinema is a good source. Back to the Future (director Robert Zemeckis) is from 1985. The first allusion was in 1986, and 381 now exist. I found 45 "Final frontiers," 13 of them including the word "space." The first television series of Star Trek was in 1966, and the first allusive title was in 1980. The uses are all straight quotes and many are questions; for example, "Atherosclerotic plaque inflammation: the final frontier?" I also found 78 close encounters, 31 of the form "Close encounters of the ... kind" (Close Encounters of the Third Kind, director Steven Spielberg, 1977).

The Good, the Bad, and the Ugly (director Sergio Leone, 1966) was used first in 1977-"Fat: the good, the bad and the ugly. The Bradshaw Lecture"-and then not again until 1986. It has since become popular, however: I found 160. Some originality exists: for example, "Enteral nutrition: how do we get more of the good and less of the bad and ugly?" Leone's earlier film in the same genre, A Fistful of Dollars (1964), has inspired only five titles, including "Two fistfuls of porridge" and "A fistful of T cells."

What about our less formal culture? Elvis Presley provides just one definite allusion: "Paclitaxel plus carboplatin: an effective combination chemotherapy for advanced non-small-cell lung cancer or just another Elvis sighting?" I found two heartbreak hotels, six suspicious minds, and 15 it's now or nevers, but these phrases are too general to be able to tell if they are allusions. There is no lonesome tonight. I found seven uses of "Knowing me, knowing you," a phrase likely to have been taken from Abba's 1977 single. Queen's Another One Bites the Dust dates from 1980, and I found 23; but Queen did not invent the saying, so are they allusions? There are no "fat bottomed girls" (Queen, 1978). Searching on Beatles' lyrics found nothing, except "To please or not to please" (Please Please Me, 1963).

Atkin, ${ }^{1}$ searching 1976-2001, found 201 titles containing the phrase "paradigm shift." The total is now 378 , including paradigms that have "shifted." 

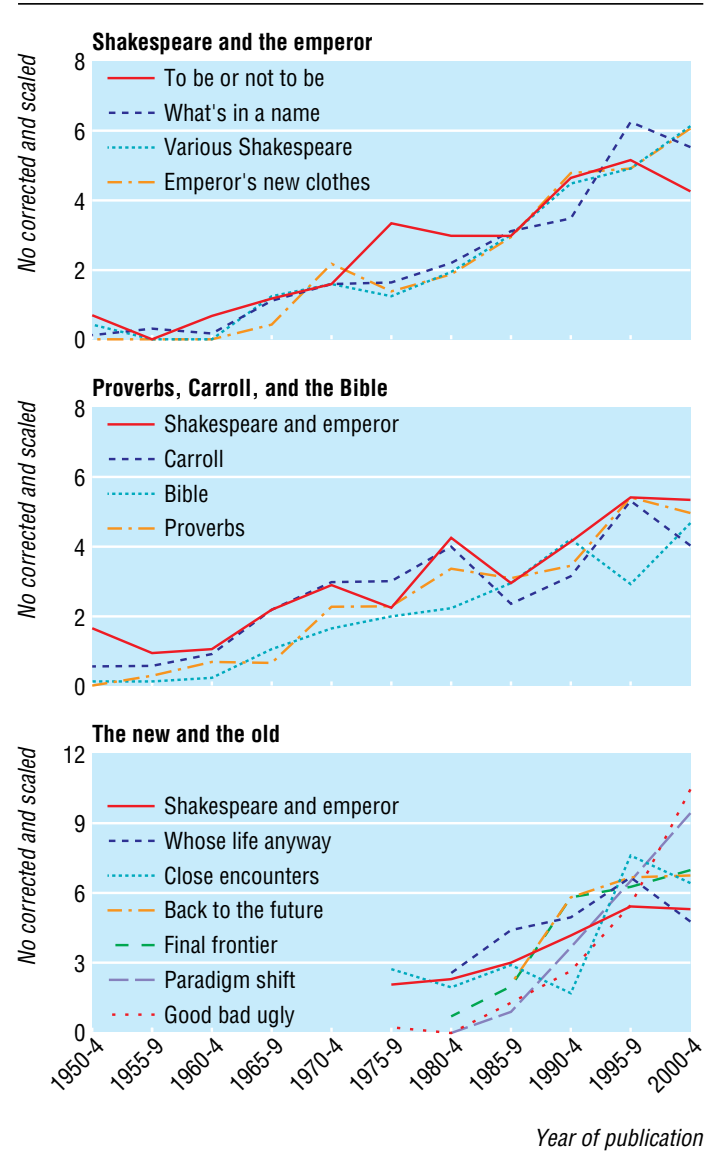

Number of allusions per five year period, corrected for number of publications per period and scaled up to a total of 100 . Solid lines in two lower graphs are an average of lines in top graph

\section{Allusory trends}

By five year period, the absolute number of all the common allusions has increased; even when corrected for total number of publications, the general trend is upward and is remarkably similar for the older allusions (figure, top). I searched on three other sources of allusions that predate Medline, to test whether this similarity has general validity. I found 331 allusions to a group of seven proverbs and 173 allusions to two quotations of Lewis Carroll. The two individual trends track one another, close to an average of Shakespeare and the emperor (figure, middle).

Half of the 303 allusions to 10 biblical sources were accounted for by 71 ten commandments (there was also one eleventh commandment and a last commandment), 56 brother's keepers (which led to eight non-biblical finders keepers), and 35 let there be lights. Biblical trends were more erratic (figure, middle). The first two biblical allusions, from May 1950, were Italian. Nearly 10\% (28) of biblical allusions were non-English, a similar proportion to emperors (20/224), and far higher than Shakespeare (21/1431). I identified another 30 biblical titles by scanning lists: for example, there were 14 allusions to camels passing though eyes of needles in a list of 25 that included camels' eyes and needles in eyes. Only 10 of 58 titles containing blessed were allusions. My favourite biblical allusion is "In the beginning was the worm: finding the secrets of life in a tiny hermaphrodite."
All the 22 allusions to "out of the mouths of babes" had titles suggesting editorial or comment rather than original research, and they had no Medline abstracts. The titles of all 13 retrieved papers otherwise containing mouths and babies were suggestive of original research, and three had abstracts (see bmj.com).

The trend for the newer allusions is also upwards (figure, bottom), although "Whose . . . anyway" may have peaked. Atkin suggested that the popularity of "paradigm shift" was declining, ${ }^{1}$ but it has overtaken most of the other newer allusions, which may be becoming more popular than older ones.

\section{Discussion}

Allusory titles will have started before Medline. Even within Medline, I will not have found all the examples of the allusions that I identified, and many others will be unidentified. Some totals may be exaggerated by indexed letters in response to original articles, although these were usually easy to spot by scanning. A richer single source than Shakespeare may exist, but I think it unlikely. I was surprised at the few biblical allusions.

The strikingly similar trends for the older allusions, the Bible excepted, presumably means that each is an independent marker of an author behaviour. Allusive titles are sparse before 1970. Perhaps authors are more likely to be allusive if they have read an allusive title.

Nonino worried that "catchy title bias" could be added to the list of systematic biases affecting biomedical publication, ${ }^{3}$ but only four of the allusions to the emperor's new clothes and 10 of the allusions to Shakespeare are indexed as clinical trials, evaluation studies, or metaanalyses. Any list of allusive titles looks like editorial and comment rather than original research, and the mouths and babies listing, although small, supports this.

DeBakey warned about colloquialisms and readers who do not speak English. ${ }^{2}$ Shakespearean allusions are uncommon in non-English papers, but more pertinent is the fact that bare titles such as "Much ado about nothing" or "Back to the future" are difficult to index and mean nothing to the reviewer or researcher.

Allusive titles are undoubtedly eye catching on journal title pages or Medline screens. Whether they really do attract readers or citations is difficult to know; it would mean comparing citations in similar fields for allusive and non-allusive titles. Thinking of possible allusions in the first place is difficult enough. Many have certainly been used enough that they are clichés, perhaps more likely to annoy than appeal. Better to think of something truly original and imaginative. Mitchell could have titled his 1982 review, "A critical review of recent treatments for myocardial infarction." His actual title, "But will it help my patients with myocardial infarction?" was much better.

I thank colleagues for suggesting allusions, especially Ed Morris. Contributors: The paper is entirely my own. I am the guarantor. Funding: None.

Competing interests: None declared.

1 Atkin PA. A paradigm shift in the medical literature. BMJ 2002;325:1450-1. DeBakey S, DeBakey L. The title: what's in a name? Int J Cardiol 1983;2:401-6.

3 Nonino F. The catchy title bias [electronic response to Atkin PA. A paradigm shift in the medical literature]. BMJ 2002. bmj.com/cgi/content full/325/7378/1450\#responses (accessed 29 Nov 2004).

4 Mitchell JRA. "But will it help my patients with myocardial infarction?" BMJ 1982;285:1140-8.

(Accepted 4 October 2005) 